\title{
A Web Analytics Approach for Appraising Electronic Resources in Academic Libraries
}

\author{
Daniel M. Coughlin \\ College of Information Sciences and Technology, The Pennsylvania State University, University Park, PA \\ 16802. E-mail: dmc186@psu.edu \\ Mark C. Campbell \\ College of Information Sciences and Technology, The Pennsylvania State University, University Park, PA \\ 16802. E-mail: mcc171@psu.edu \\ Bernard J. Jansen \\ College of Information Sciences and Technology, The Pennsylvania State University, University Park, PA \\ 16802. E-mail: jjansen@ist.psu.edu
}

\begin{abstract}
University libraries provide access to thousands of journals and spend millions of dollars annually on electronic resources. With several commercial entities providing these electronic resources, the result can be silo systems and processes to evaluate cost and usage of these resources, making it difficult to provide meaningful analytics. In this research, we examine a subset of journals from a large research library using a web analytics approach with the goal of developing a framework for the analysis of library subscriptions. This foundational approach is implemented by comparing the impact to the cost, titles, and usage for the subset of journals and by assessing the funding area. Overall, the results highlight the benefit of a web analytics evaluation framework for university libraries and the impact of classifying titles based on the funding area. Furthermore, they show the statistical difference in both use and cost among the various funding areas when ranked by cost, eliminating the outliers of heavily used and highly expensive journals. Future work includes refining this model for a larger scale analysis tying metrics to library organizational objectives and for the creation of an online application to automate this analysis.
\end{abstract}

Received April 1, 2014; revised July 31, 2014; accepted August 15, 2014

(C) 2015 ASIS\&T • Published online 13 April 2015 in Wiley Online Library (wileyonlinelibrary.com). DOI: 10.1002/asi.23407

\section{Introduction}

A large research university can spend tens of millions of dollars or more annually on electronic resources (Furlough, 2012). It has become common for research libraries to spend large portions of their collection budgets on these resources; ongoing annual subscriptions account for nearly $70 \%$ of the collection budgets in academic libraries (Kyrillidou, M., Morris, S., \& Roebuck, 2013). When libraries stored only physical copies of journals, there were limitations based on physical space within the library for how many journals a library could subscribe to and subsequently store. The digital era has alleviated most space limitations and arguably removed the barriers to entry around publishing. These factors have given rise to the increase in number of electronic resources available to libraries, with financial rather than physical constraints being the primary limiting factor. Today, a university library can have access to more than 100,000 journal titles from myriad content providers. Providing ubiquitous access to a vast amount of research material is a goal that has been realized by many library electronic resources departments.

What has become challenging in this environment is to understand the value of the resources to which a university library provides access. Specifically, what resources provide real value to the community? What resources are underutilized? What resources are unnecessary? Given the constantly changing nature of electronic journals and libraries' attitudes toward them, as well as the inexorable advance of technology, one cannot assume that past answers apply today (West, Miller, \& Wilson, 2011). Instead, it is 
important to create a set of analytic metrics with which institutions can perform their own evaluation to understand their specific community's needs (i.e., effectiveness) and also to gauge the process by which they provide these resources (i.e., efficiency). To do this, it is imperative that libraries know both the content to which they subscribe and the value of that content in order to manage these electronic resources effectively. Although this may seem obvious, managing such collections effectively and efficiently based on quantitative metrics has become increasingly difficult because of the complexity of subscription models and the sheer amount of data.

Here, we categorize the varied subscription models from content providers into three subscription general types, aggregations, databases, and packages, defined as follows.

- Aggregations are large collections of journals, sometimes numbering in the thousands, from various content providers on numerous subjects that are purchased through a single provider. Access to individual titles from these deals can be subject to change with or without notice; however, they provide a way to gain access to a large number of titles.

- Databases are search indexes for a set of journals, typically centered on a particular subject. These search indexes may vary in terms of what they inventory, with some indexes containing abstracts and some containing full-text indexing capability. Access to the search index results set does not necessarily imply access to the article in the results set, because the level of access varies by database.

- Packages are essentially direct subscriptions to journals that provide access to scholarly articles contained within those journals. Sometimes these are packages of one (i.e., one journal). Other times, a package may contain multiple journals. The complexity can come when a specific package or group of packages is sold together and the library cannot buy a single journal title but rather must purchase the entire package and the associated titles within that package. Thus, a package may provide access to only one journal. Packages can also provide access to a handful of journal titles for a single price without a list price for each journal title.

Note that, throughout this article, we use the term journal in a broad sense of representing all possible types of titles, including journal articles, journal notes, conference proceedings, book reviews, and so on.

The complexity in understanding these subscription types is based on how providers manage the subscription models in relation to how libraries may desire to purchase the subscription. By analogy, imagine creating a music collection from various online music distributors. In this scenario, you may want access to a particular album by the Beatles and could buy that album individually, but you also want an album by a lesser-known band, say Built to Spill; however, you cannot buy the Built to Spill album individually. Built to Spill has licensed their album only to be sold by iTunes, and iTunes sells this album along with a collection of other albums as one set of musical artists. To get the album from Built to Spill, you have to buy the set of 10 from iTunes. This situation is analogous to-on a much smaller scalepackages (the individual Beatles' album) and aggregations (the Built to Spill collection).

Now, imagine that, once you have bought this collection of independent musical artists, you realize that this set of albums also has the album by the Beatles, which would be great if you had known in advance; however, you have now paid for this album twice, resulting in duplication and wasted costs that could be better spent on other albums. This situation is analogous to buying a package from a content provider only to find out that it is also included in a larger aggregator deal the library has also purchased.

The situation is even more complex. Say you want to purchase another individual album by The Beatles that has previously unreleased material. Unfortunately, you cannot just buy this album; the provider has decided to bundle this album in a "box set" and sell it as part of a package with four other albums. Now you have to pay for five albums to get the one you would like. This situation is again analogous to package deals with journals.

Finally, given that now you have all of this music, the ability to search it becomes increasingly valuable as the size of your collection grows. The search appliance you buy indexes according to musical areas and in some cases it can index all the songs on an album and in some cases it cannot. In some instances, it returns results that are outside of your collection just to make you aware that other music outside of your collection exists to meet your search criteria. Although it is helpful to become aware of an album that you might not have previously known about, there is confusion at times on what results your searches return. This situation is analogous to databases in which some of the content is full text and other content in the same database is only an abstract.

These situations are similar to how the three subscription models (aggregations, databases, and packages) can work within an electronic-resources environment at a major library. At the individual level, as with our music metaphor, measuring value can be difficult. In this multifaceted content environment of the modern university research library, with tens of thousands of titles and millions of dollars at stake, it has become increasingly difficult to measure the value of the content collection, and our methods of evaluation and tools for evaluation have not kept pace.

The motivation for our research is to address this complex issue by modernizing the methods of and tools for evaluation. The goal of this article is to provide a foundation for a framework to evaluate electronic resources at a university library on a large scale. We build this framework by developing and analyzing key performance indicator (KPI) metrics for a substantial set of journals that has a sizable impact on (a) content, (b) titles, and (c) usage at a major research university library. Although we focus on packages in the research reported here, this evaluation approach can be combined with additional metrics for an analysis of databases and 
TABLE 1. Focus of study: subscription and metrics applied to create a framework for evaluating electronic resources at research libraries.

\begin{tabular}{|c|c|c|c|}
\hline Study type (KPIs) & Subscription type(s) & Potential metric & Definition \\
\hline Cost & Packages, Databases, Aggregations & $\begin{array}{l}\text { Cost per click } \\
\text { Cost per search } \\
\text { Cost per title }\end{array}$ & $\begin{array}{l}\text { Number of clicks per download } \\
\text { Number of searches/cost for access } \\
\text { Number of titles within an aggregation }\end{array}$ \\
\hline Titles & Packages, Databases, Aggregations & $\begin{array}{l}\text { Duplicate titles } \\
\text { Unique titles } \\
\text { Number of titles } \\
\text { Area of study } \\
\text { Full-text index } \\
\text { Abstract index }\end{array}$ & $\begin{array}{l}\text { Number of times that this title appears in collection } \\
\text { Number of unique titles in index } \\
\text { Total number of titles in index } \\
\text { Disciplines covered by index } \\
\text { Access to full text provided } \\
\text { Access only to abstracts provided }\end{array}$ \\
\hline Usage & Packages, Databases & $\begin{array}{l}\text { Citations/impact factor } \\
\text { Cost per use } \\
\text { Interlibrary loan (ILL) use }\end{array}$ & $\begin{array}{l}\text { How often journal is cited both locally and globally } \\
\text { Successful full-text downloads/cost } \\
\text { Comparing cost per use with cost of ILL }\end{array}$ \\
\hline
\end{tabular}

aggregations to create a quantitative decision framework to evaluate university library electronic resources.

There are at least three areas to examine within electronic resources: (a) cost, how much is spent on these resources; (b) titles, the number of resources provided for a particular discipline; and (c) usage, how often these resources are used. We have created a classification based on our own analysis as well as on metrics used in prior studies on electronic resources, subscription type, metrics, and the metric definition (see Table 1). The potential metric column displays the different metrics related to key KPIs that might be used to determine the value of that subscription, along with the definition of that metric.

Two global approaches currently used to evaluate the value of electronic resources are journal citation reports (J) and expert perceptions; however, these overarching approaches cannot be the sole resource for analysis for a research library. Coleman (2007) states that journal impact factor does not directly equal journal quality, because journal quality is multifaceted. Additionally, the two primary methods of journal rankings, $\mathrm{J}$ and expert perceptions, have been shown to be flawed, and these limitations provide a compelling justification for further investigating journal value (Enssle \& Wilde, 2002).

This research provides an analysis of journal value, focusing on the management of journals by comparing a holistic perspective (looking at all journals equally) and a funding area perspective of categorized journals (correlated to the discipline for content of the journal). This comparative approach allows a quantitative perspective of the impact that journal management has on a particular funding area to provide a structure for evaluating and potentially eliminating superfluous journals.

\section{Related Work}

\section{Is This Subscription Data Useful?}

The digitization of scholarly resources has created a benefit for researchers by providing ubiquitous access to academic content; however, the proliferation of online content has made it difficult for libraries to navigate in the context of collection management, which is "the set of activities which is intended to ensure that a library's internally held and externally provided resources meet the needs of its users, leads to weeding and acquisition" (Schwartz, 2000, p. 389). The notion of weeding out collections that provide little or no value is a primary objective for serving the needs of researchers. Tight library budgets create an environment in which waste has to be eliminated, particularly concerning online collections, because they make up a large portion of the budget and are targets for scrutiny. Historically, libraries have been able to manage collection use through the circulation of content within the library. The ability to compute the demand for content when accessed from the library is simpler than tracking this information from a multitude of digital access points. "One of the problems of a 'library without walls' is just that - the absence of physical dividing lines that separate the library from the rest of the world, and that also give us some sense of being able to control, or at least see, our collections and our users" (Schwartz, 2000, p. 390). Libraries recognize the need for data collection management in order to make strategic decisions regarding electronic resources. However, these efforts are typically done on a case-bycase basis and there is currently no way to do this type evaluation systematically (Derven \& Kendlin, 2011; De Bellis, 2014).

The intricacies within subscriptions quickly become apparent when looking at the sheer number of journal titles that an academic library at a major research institution has. For example, the library used in our study has access to over 100,000 titles from subscriptions through journals, databases, and aggregations. This quantity is important to understand because, if all of this information is not used, there could be savings in some areas without significantly affecting the electronic resource collection. In fact, some of these providers are not particularly selective regarding the quality of scholarly material to which they and, in turn, university libraries provide access (Vaughan, 2012). The potential lack of quality content in host providers leads one to question 
their worth in some situations and to suggest that they may ultimately do more harm than good because student researchers, having less experience and knowledge of good scholarly publications, believe higher quality content exists by just being in a library content collection. This underscores the need for fewer lower-tiered electronic journals and a greater amount of digital scholarly work because students will choose the convenience of going online for research (Bartsch \& Tydlacka, 2003).

Separate from the amount of data, but of equal importance, is the cost associated with providing access to all of these journals. The cost goes beyond subscription fees; there are operational costs associated with both human and technical resources dedicated to providing access to this content (Montgomery, 2000). According to King and Tenopir (1998), skyrocketing journal subscriptions are directly linked to having online access to journals. This increase in subscription cost has led the library to seek multi-year contracts to provide access to most or all of a commercial publisher's journals. These multi-year contracts have led to higher costs (Blecic, Wiberley Jr., Fiscella, BahnmaierBlaszczak, \& Lowery, 2013).

\section{Complexity on Online Content}

With access to over 100,000 titles, the complexity based on the collection size alone is evident. Additionally, monitoring journal use is problematic because of the various types of subscriptions, methods of access, and tracking information. For example, tracking all the relevant usage data on journals provided by an aggregator may be difficult because aggregations provide access to a fluctuating number of journals throughout the year. You may have access to a journal in January and no longer have access in March. The challenge libraries have in gaining access to track journals within aggregate packages is well documented (Chambers \& So, 2004; Duranceau, 2002). These various subscription models also come with a number of methods to access content. For example, not all advertised full-text access is always full text. In some cases, embargo periods take full text out of indexes after the article has been printed in an effort to keep value in the print version of a journal (Blessinger \& Olle, 2004). This makes it more straightforward to monitor use of a journal to which you have an annual subscription and to monitor the price of a single subscription rather than determining a method to break down the price of each journal within a package of 10,000 titles from an aggregator or varying levels of full-text access within a database.

Theoretically, accessing digital resources could lead to a more streamlined process, allowing simple programming scripts to aggregate data for librarians to analyze; however, the change of access points from the physical library to multiple remote servers presents a hurdle that libraries have yet to overcome (Duranceau, 2002). The process for tracking circulation data was manual before the process was online, but it was also stewarded by the library and therefore could be amended to meet the workflow needs of the individual library. Now, content and the data specifying the use of the content are stored on remote servers by publishers.

Remote access to content that is stored on third-party servers presents two stumbling blocks in the form of standardization and accuracy. Standardization in storing the access $\log s$ in the same format on all servers across all publishers is essential so that the same method for retrieving usage statistics can be used no matter who is the content provider. The issue of accuracy is one of inaccurate logs that would lead to erroneous KPIs for journals. In some cases, publishers lack consistency in how they calculate particular statistics, for example, how searches are logged in a database. Additionally, publishers do not provide information about how they collect their data (Duy \& Vaughan, 2003). Even if publishers did provide methods for how statistics were created, unless there is a standard for the metrics, it would add yet another distinction to track and analyze.

Perhaps even more troubling is that, beyond standardization for counting statistics on resource usage, these usage statistics many times lack accuracy. Duy and Vaughan (2006) tracked usage statistics locally to compare with the statistics provided from publishers and found that in some cases usage was higher locally and in other cases lower locally.

It is important for libraries to make sure that usage data are accurate to ensure effective collection management (Duy \& Vaughan, 2003). The only way to ensure accuracy is to track usage statistics and to compare those local statistics with those of publishers. This does not mean that usage errors are made with malicious intent. The environment that exists with multiple access points, content that exists with multiple publishers, content that is no longer accessible during a calendar year, and the sheer volume of data being accessed results in usage statistics not being easily attainable and in some cases unattainable. Furthermore, the modes of delivery for these statistics can be numerous and cumbersome. These various modes include separate spreadsheets to download for each provider (instead of one spreadsheet for all titles), requiring manual data curation; copying data from a website to a spreadsheet or e-mail attachments; and, in the worst scenario, having no data at all.

\section{Standards for Tracking Online Content}

Although standards are not implemented with complete coverage throughout electronic journal publishing, some standards do exist. COUNTER (Counting Online Usage of Networked Electronic Resources) is a nonprofit organization with an international advisory board made up of library and publishing specialists. Since the initial COUNTER Code of Practice in 2003, this international consortium has been "setting standards that facilitate the recording and reporting of online usage statistics in a consistent, credible and 
TABLE 2. Usage reports and definitions from COUNTER as of April 2012

\begin{tabular}{|c|c|}
\hline Report & Description \\
\hline Journal Report 1 (JR1) & $\begin{array}{l}\text { Number of successful full-text article } \\
\text { requests by month and journal }\end{array}$ \\
\hline $\begin{array}{l}\text { Journal Report 1a } \\
\qquad(\text { JR1a-optional) }\end{array}$ & $\begin{array}{l}\text { Number of successful full-text article } \\
\text { requests from an archive by month } \\
\text { and journal }\end{array}$ \\
\hline Journal Report 2 (JR2) & $\begin{array}{l}\text { Access denied to full-text articles by } \\
\text { month, journal, and category }\end{array}$ \\
\hline $\begin{array}{l}\text { Journal Report } 3 \\
\text { (JR3-optional) }\end{array}$ & $\begin{array}{l}\text { Number of successful item requests by } \\
\text { month, journal, and page type }\end{array}$ \\
\hline Database Report 1 (DB1) & $\begin{array}{l}\text { Total searches, result clicks, and record } \\
\text { views by month and database }\end{array}$ \\
\hline Database Report 2 (DB2) & $\begin{array}{l}\text { Access denied by month, database, and } \\
\text { category }\end{array}$ \\
\hline $\begin{array}{l}\text { Platform Report } 1 \text { (formerly } \\
\text { Database Report 3-DB3) }\end{array}$ & $\begin{array}{l}\text { Total searches, result clicks, and record } \\
\text { views by month and platform }\end{array}$ \\
\hline $\begin{array}{l}\text { Journal Report } 4 \\
\text { (JR4_optional) }\end{array}$ & $\begin{array}{l}\text { Total searches run by month and } \\
\text { collection }\end{array}$ \\
\hline
\end{tabular}

Note. Reports not listed as optional must be provided by vendors to be considered COUNTER compliant.

compatible way" (COUNTER, 2012, p. 3). COUNTER maintains a list of vendors who are COUNTER compliant for journals and databases (as well as books and reference works). There are a number of usage reports listed in Table 2 that display the report name and the description of the data found in the report for vendors or publishers to help with various types of metrics.

COUNTER's list of registered vendors provides a chart of vendor name and the type of report with which they are in compliance, as shown in Figure 1. Figure 1 provides a snapshot of how few vendors meet all of the COUNTER compliance reports as well as an indication that JR1 reports are the most common.

Figure 1 indicates that a vendor may provide one type of standard report while not providing all the reports to be fully COUNTER compliant. For example, Alexander Street Press Inc. (see row 1 of table in Figure 1) provides JR1 and DB1 reports but does not provide the JR2 and DB2 reports needed to be considered COUNTER compliant; however, the reports that they do provide allow analysis of certain metrics on full-text article downloads (JR1). Thus, being COUNTER compliant is an ideal situation for further evaluation, but there is value in providing any number of these reports to allow investigation and analysis.

The National Information Standards Organization (NISO), a nonprofit organization that develops standards and protocols to manage information in our changing digital environment (Needleman, 2006), in conjunction with COUNTER reports, defined the Standardized Usage Statistics Harvesting Initiative (SUSHI). SUSHI is a web-request framework for eliminating the manual labor-intensive activities of collecting COUNTER reports. In short, SUSHI allows organizations automatically to download COUNTER reports that are stored on several publishers' servers instead of requiring a librarian to go to each publisher's website, download the various COUNTER reports for each publisher, and then organize and store the reports somewhere accessible for other librarians to investigate.

An additional standard that NISO designed to alleviate some of the database access confusion is OpenURL. When a database provides a search index to abstracts for journal articles but does not provide access to the full text of the journal article, OpenURL can help provide access. If a library has access to the full text of a journal article through a deal with another content provider, this access can be granted via OpenURL. OpenURL provides additional metadata in the URL (along with a base URL) to query additional library holdings and provide direct links to the journals in which the full text of the article is accessible. The base URL in an OpenURL points to a "link resolver" that is capable of performing a query against the library's holdings based on the additional metadata (i.e., ISSN, author, title) provided in the link (McDonald \& Van d Velde, 2004).

\section{Metrics and In-House Bookkeeping}

There are three categories of data that seem to be of high priority for making decisions regarding electronic resources. Those categories are (a) titles (to what do we have access?), (b) use (how often do we use it?), and (c) cost (how much do we pay for access to it?). The current methods used to manage electronic journals should improve simplicity, affordability, and interoperability with discovery tools (OpenURL, large-scale web discovery, etc.) and integrated library systems (ILS; used to track library assets, and billing) products (West et al., 2011). The University of Illinois at Chicago developed an internal system, Database of Library Licensed Electronic Resources (DOLLeR), to assist in the management of electronic resources and improve efficiency, particularly with regard to licenses and subscriptions. In house systems created to manage electronic resources have a variation in scope and complexity due to the range of technical expertise that exists at local institutions to help support the creation and maintenance of these systems.

It is important for libraries to track data internally and to compare these data with data from publishers not only to ensure the accuracy of data that publishers provide but also because any major differences could signal a problem in a service the libraries provide (Duy \& Vaughan, 2003). Internally tracking this information becomes an even higher priority given that the most common places for librarians to check for changes in managing electronic records are with the publisher and technical services (West et al., 2011). Data on cost and usage can be combined to create important KPIs for which journals are or are not providing value to the community. These data points are necessary during a time of shrinking budgets in an effort "to do more with less" (Leon $\&$ Kress, 2012). Perhaps the most frequent metric discussed 
From 1 January 2014 only Vendors and Usage Reports included in this list may be regarded as being COUNTER compliant

\begin{tabular}{|c|c|c|c|c|c|c|c|c|c|c|c|c|c|}
\hline & \multicolumn{13}{|c|}{ Standard Reports Provided by Vendor } \\
\hline & \multicolumn{4}{|c|}{ Journal Reports } & \multicolumn{3}{|c|}{ Database Reports } & \multicolumn{5}{|c|}{ Book Reports } & \multirow{2}{*}{\begin{tabular}{|l|} 
Multimedia \\
Reports \\
MR1 \\
\end{tabular}} \\
\hline Vendor & JR1 & JR1GOA & JR2 & JR5 & DB1 & DB2 & PR1 & BR1 & BR2 & $B R 3$ & $B R 4$ & BR5 & \\
\hline Alexander Street Press & Yes & Yes & Yes & Yes & Yes & & & & & & & & \\
\hline Atypon & Yes & Yes & Yes & Yes & & & & & & & & & \\
\hline ebrary & & & & & & & Yes & & Yes & Yes & & Yes & \\
\hline Editions Techniques de l'Ingenieur & Yes & & Yes & & & & & & & & & & \\
\hline Elsevier Science Direct & Yes & & & Yes & & & Yes & & Yes & & & & \\
\hline Gale Cengage & Yes & & & & Yes & Yes & & & Yes & & & & \\
\hline International Association for Energy Economics & Yes & & & Yes & & & & & & & & & \\
\hline Jaypee Brothers Medical Publishers & & & & & & & & & Yes & & & & \\
\hline Optical Society of America & Yes & Yes & Yes & Yes & Yes & & & & & & & & Yes \\
\hline Ovid Technologies & Yes & & Yes & Yes & Yes & Yes & Yes & Yes & & Yes & Yes & & \\
\hline Safari Books Online & Yes & & Yes & Yes & Yes & Yes & Yes & & Yes & Yes & Yes & & \\
\hline Scholarly iQ & Yes & Yes & Yes & Yes & Yes & & & & & & & & Yes \\
\hline Thieme Medical Publishers & & & & & & & & & Yes & Yes & & Yes & \\
\hline Thomson Reuters (Web of Science) & & & & & Yes & Yes & & & & & & & \\
\hline & & & & & & & & & & & & & \\
\hline & & & & & & & & & & & & & \\
\hline & & & & & & & & & & & & & \\
\hline
\end{tabular}

FIG. 1. Listing of vendors and the corresponding compliance for each COUNTER report available. Report accessed from http://www.projectcounter.org/r4/R4Overview_Dec2013.pdf. [Color figure can be viewed in the online issue, which is available at wileyonlinelibrary.com.]

in the literature is usage: how often was this resource accessed, how often was this resource searched, and how often was this resource downloaded?

Measuring resource usage is invaluable; tracking how often a resource is used and then combining that information with how much the resource costs can govern the selection or cancellation of a resource. Increased prices along with fragmented titles and content that is duplicated across various database are among the motivating factors for maintaining usage statistics (Medeiros, 2007). Weaknesses exist in measuring usage statistics; for example, the importance of a journal within a particular discipline cannot be measured simply by how often it is used (Enssle \& Wilde, 2002). One weakness of global data, such as J, is the inability to account for a multidisciplinary approach; not all disciplines operate in the same way with respect to citing prior work. Therefore, there should be evaluation by categorization that uses groups initially to define and categorize journals prior to determining value. This should be done because applying the same methods and measures to evaluate all disciplines has been proved to be inaccurate (Bensman, Smolinsky, \& Pudovkin, 2010). Furthermore, some fields are actually interdependent, and comparisons based on subject matter (i.e., management literature is dependent on social science literature) can be problematic (Neeley, 1981). Even with these caveats, it is generally accepted that usage is a fundamental indicator of determining the value of electronic resources (Metz, 1992); therefore, metrics involving usage have an influence on the significance of these resources.

Understanding the connection among cost, titles, and usage provides an opportunity for evaluating electronic resources more equitably by comparing resources that are funded by the same area and subsequently serving a corresponding area. This relationship provides insight into how users are being affected by usage statistics and the audience is being affected based on the funding area. Furthermore, usage-based metrics correlated with funding area provide a means for libraries to measure electronic resource value within these funding areas. Results from this research can serve a variety of purposes, including recommendations for eliminating resources that provide little value, recommendations for additional funding in areas that provide high value, and recommendations for funding in areas that are not equitably represented.

The primary methodology approach of this research is web analytics, which is the measurement, collection, analysis, and reporting of Internet data for the purposes of understanding and optimizing web usage (Jansen, 2009). Although web analytics cannot measure motivation or satisfaction, it provides a method to evaluate online behaviors, correlate usage with other available data, and standardize information across data sets (Jansen, 2009), including financial information (Jansen \& Molina, 2006; Ortiz-Cordova \& Jansen, 2012). One of the contributions from this research is the creation of advanced web metrics based on combining raw numbers such as JR1 frequencies, cost data, and funding areas. These advanced metrics will help in evaluating how successful the library is at meeting the goal of providing access to valuable content. The statistical model used here is analysis of variance (ANOVA), which quantifies the variance of the means among categories. It is used to quantify the variance of usage among funding areas. 


\section{Research Objective}

Research Question: Is there a significant difference in cost and usage among the various funding areas (i.e., titles)?

The larger research question aims to determine quantitatively whether differences in cost and use affect topical funding areas. If it is true that there is a significant quantitative difference among these categories, this will illustrate the need to evaluate journals based on a funding area, as opposed to considering all journals at one time, for a more equitable evaluation; however, if the institutional goal is money savings, then a holistic perspective may be more significant than user or funding-area equity. However, if the goal is to investigate journals that have less usage and subsequently less impact on users, perhaps it is better to evaluate journals by funding area. By answering this question, we can create KPIs to tie the institutional goals to metrics for a more specific evaluation.

Our research site allocates purchases of online content via a mechanism known as topical funding areas, which aligns purchases with the various academic areas of the university. We categorize cost and usage into 10 funding areas (listed in Table 3) as provided by the library financial reports to indicate the source of funding for each resource. We then compare the cost, titles, and usage among each of these funding areas. We next gathered cost, title, and usage data for a subset of electronic resources from a major research university library. Not all universities libraries use an exact funding method, but a similar approach could be implemented with similar funding schemes that seek to align online content purchases with academic areas.

Hypothesis 1: Usage is unevenly distributed among the 10 funding areas based on the least used one third (33\%) of all journals.

We define usage as the number successful full-text article downloads from a particular journal in 2012, which is of primary importance in measuring a journal's demand. We use an ANOVA to measure the variance of usage among the funding areas to determine whether the usage is unevenly distributed within the 10 funding areas.

TABLE 3. Funding area names and their corresponding abbreviation.

\begin{tabular}{ll}
\hline Funding area & Abbreviation \\
\hline 1. Arts and humanities & A\&H \\
2. Business & Bus \\
3. Earth and mineral sciences & EMS \\
4. Education & Ed \\
5. Engineering & Eng \\
6. Life sciences & Life Sci \\
7. Physical and mathematical sciences & P\&MS \\
8. Social sciences & Soc Sci \\
9. Nothing & Nothing \\
10. All & All \\
\hline
\end{tabular}

Hypothesis 2: Cost is unevenly distributed among the 10 funding areas based on the least used one third (33\%) of all journals.

The cost of these journals is of primary importance in evaluating the journals to which a library subscribes on an annual basis. Ranking the journals in order of usage and then taking the least used one third of journals can mitigate some presumed bias in spending based on funding areas. Additionally, this analysis may offer the ability to find funding areas that are true outliers and that appear to have very high costs.

Hypothesis 3: Usage is unevenly distributed among the 10 funding areas based on the least expensive one third (33\%) of all journals.

The importance of usage in evaluating journals has been established; here we analyze whether there is a significant distinction in the usage of the funding areas based on the least expensive journals. Ranking the journals by price in this analysis normalizes some of the disparity in price among the journals and will provide insight into whether that price normalization within the funding areas leads to parity in usage among the funding areas.

Hypothesis 4: Titles are unevenly distributed among the 10 funding areas based on the least expensive one third (33\%) of all journals.

Classifying the journals by funding area and ranking in order of most expensive to least expensive within each funding area should allow a level of uniformity within each area of spending. There may be an assumption that ranking journals by price within each funding area will eliminate any of the parity that exists among the funding areas. We chose to present results in terms of top one-third, middle one-third, and bottom one-third for ease of presentation and considerations of space, while still retaining the ranking and prioritizing inherent in the methodological approach versus discussing thousands of journals. Naturally, in an actual university library implementation, access to the full ranking of journals would be available.

Data from these four hypotheses will provide a contribution to the broader research question (Is there a significant difference in cost and usage among the different funding areas?). Affirmation of this question will suggest that an analysis of journals (based on usage or cost) must occur within the classification of funding areas because there is significant variance of usage and cost among the funding areas.

\section{Methods, Data Preparation, and Analysis}

\section{Data Collection Site}

Data were collected from a large, tier 1 research university with more than half a billion dollars in annual research funding, 17,000 faculty, and 100,000 students. The library for this university is in the top 10 Association of Research Libraries (ARL) library investment index (frequently referred to as ARL ranking). This library system consists of 36 separate locations and nearly 5 million catalogued items. 
TABLE 4. Example of how data are displayed on spreadsheet to determine what may be considered a package deal and what may be considered a line item purchase.

\begin{tabular}{llcccc}
\hline Order ID & Journal name & ISSN & Database & Provider & Cost \\
\hline PO-1234 & $\begin{array}{c}\text { Mechanisms of Ageing and } \\
\text { Development } \\
\text { Ageing Research Reviews }\end{array}$ & - & ScienceDirect & Elsevier & \$247.05 \\
Acta Astronautica & - & ScienceDirect & Elsevier & Ageing purchased together \\
PO-1235 & AcienceDirect & Elsevier & $\$ 4,991.57$ \\
\hline
\end{tabular}

In 2012, there were over 4.5 million successful full-text downloads of electronic resources from this library.

\section{Data Collection Cost}

The first step was to get a list of the electronic resources that the university library purchased in 2012. One would think that these data are simple to access. It is not the case; instead, it is one aspect of the complexity of measurement in the library electronic resources domain. Those data are housed in a software package called Workflows, which is a library integration system (LIS). The data generated for this study included a list of all active payments for the fiscal year 2011-2012. Active payments are subscriptions that are paid for based on an annual charge. For this research, there is no inclusion of one-time payments that might have been made during the 2011-2012 fiscal year. Free electronic resources are not included; some back files (journals from previous years) are provided free, and those are not specifically included from current year downloads. Publishers have yet to determine how to provide, or they do not make available, logging data on the publication year for a journal, so it is not possible to measure journal access by publication year; for example, we cannot distinguish whether journal A published in 1998 was accessed 100 times in 2012 or if journal A published in 2008 was accessed 500 times in 2012; we can only distinguish that journal A was accessed 600 times in 2012.

The fiscal calendar adds another layer of complexity; the university library financial year runs from July to June, but vendor contracts typically run from January to December. In some ways, this may actually be helpful because the library plans the budget for the upcoming year in advance of having to make annual subscription deals. For example, in July of 2012, the library knows how much money the department should have to spend on subscriptions in January of 2013. This complexity may make for easier planning than when the budgets lined up exactly because it would be hard to decide what journals should be purchased for January 2013 if the funds available were not granted until that time. On the other hand, it does provide confusing analysis when incorporating the cost of resources as contracts with providers for journals are not stagnant. In this example, a library pays the provider $\$ 10,000$ for a journal in January of year 1 , and in January of year 2 the price goes up $5 \%$ to $\$ 10,500$. If the library managers have no prior knowledge that the journal price is going to increase, then they cannot accurately plan. Additionally, the advanced knowledge of an increase would have to be more than 6 months to submit budget requests on time. Even if there is prior knowledge that the cost will go up, there are only 6 months of year-1 data to analyze for spending in year 2 . This temporal discrepancy can complicate a cost analysis.

The list provided for the annual subscription data contains the following information: purchase order ID, journal name, ISSN, database that indexes the journal, provider (from whom the journal/database is purchased), cost (annual dollars spent), and notes (information to indicate whether the purchase is part of a package or how many titles are included in the item). For example, Table 4 gives a snapshot of a spreadsheet. The top two rows, Mechanisms of Ageing and Development and Ageing Research Reviews, are examples of how a journal package may be grouped. The third row displays a simpler example, giving a journal an exact price and ISSN number to match for JR1 reports.

Each line item in this spreadsheet represents a payment that was made and any number from one to 20,000 titles that may be available because of the purchase for that resource. This is how the payment information is shared for the 3,474 items that represent over 100,000 titles and $\$ 10,193,706.96$ (\$10.2 million) in 2012 subscription purchases (Table 4).

\section{Data Collection Usage}

Capturing the usage data from external sources was an additional stream (or streams) of data. The journal reports that provide information on successful full-text downloads (JR1) are provided by the vendors of those journals in separate spreadsheets. The next step of data collection was to gather 34 of these spreadsheets (when available) and link the use information in these spreadsheets with the cost information from the internal spreadsheets into a database. Linking this information provides an easier mechanism to sort, search, browse, aggregate, and view data and also allows for more robust analytics such as cost per use based on these raw numbers for cost and usage.

To link this information-internal data provided from financial reports (see Table 5) and external data provided from journal usage reports (see Table 6) - it was necessary to import the spreadsheets to corresponding database tables to simplify further manipulation. The parsing of these spreadsheets to insert the data into a MySQL database is performed 
TABLE 5. MySQL format for journal table within database used to import data from spreadsheets for financial data to link with JR1 reports.

\begin{tabular}{ll}
\hline Column name & Column type \\
\hline PO & String \\
Funding_Area & String \\
Has_JR1 & Boolean \\
Found_by_issn & Boolean \\
Name & String \\
ISSN & String \\
Platform & String \\
Publisher & String \\
Provider & String \\
Price & Decimal \\
Cost_per_use & Decimal \\
Total_download & Integer \\
Pdf_download & Integer \\
HTML_download & Integer \\
Citations & Integer \\
Authorship & Integer \\
Notes & String \\
Titles & String \\
\hline
\end{tabular}

TABLE 6. MySQL database table used to import the JR1 reports from spreadsheets into the database.

\begin{tabular}{lc}
\hline Column name & Column type \\
\hline Name & String \\
Publisher & String \\
Platform & String \\
ISSN & String \\
Total_download & Integer \\
Pdf_download & Integer \\
Html_download & Integer \\
\hline
\end{tabular}

via the Ruby programming language. Ruby was selected because the Ruby on Rails web framework provides an easy method to create web pages on top of our data model.

The university library has a business agreement with Serial Solutions for several library services, one of which is to aggregate a portion of patrons' usage of the library's electronic resources. Publishers that provide access to the journals store the usage information in a JR1 format according to the standard set by COUNTER. A librarian with authorization to Serial Solutions can log onto that administrative website and download any JR1 report that has been obtained from a provider within the past year. Serial Solutions is able to obtain information on journals only if the provider has formatted the usage statistics into JR1 format; if the data do not comply with this format, then they are not downloaded. Serial Solutions provided 34 JR1 reports for 44,833 journals in 2012; however, some data were incomplete, containing usage statistics for only half the year. In these cases, an average was created based on the usage for the number of months for which data have been provided and filled in the remaining months with that average. A Ruby Rake task, a script written in the Ruby programming language, was developed to parse the 34 spreadsheets and insert it into a database table "JR1" (see Table 6) and the internally held financial data into a table "Journal."

At this point, all 3,474 items purchased and 44,833 JR1 reports for 2012 were stored in separate tables within the database. Storing the publisher-supplied JR1 reports and the locally supplied financial reports in the database allowed for easier manipulation, faster querying, and more dynamic displaying and filtering of the information as opposed to a relatively static spreadsheet.

Further work had to be done to link the external usage data to the internal financial data. The method used to link the items for which the library actively paid in 2012 and the JR1 reports from 2012 was to loop over each of the 3,474 items and determine whether there was a matching item in the JR1 report, a match being determined first by ISSN, and, if that did not provide a match, then journal name was used. Once the financial data were linked to the usage data, we could start to evaluate both cost and usage based on internal categories (i.e., funding area) and begin to create more advanced performance metrics such as annual price/annual downloads $=$ average cost per user $(\mathrm{CPU})$. Furthermore, there was now a web interface (see Figure 2) enabling easy search, browse, and sort capabilities for all of this information.

\section{Data Selection}

Rather than investigate the entire online content collection for the library, we chose a substantial subset that also facilitated rapid verification of the model. The subset of electronic resources used was the 1,074 electronic resources from Elsevier's ScienceDirect database. These data were chosen because these journals represent over $\$ 2.8$ million in annual subscription fees (nearly $30 \%$ of all annual subscription fees for this library), received nearly 1 million downloads in $2012(995,126)$, and have titles funded from all 10 areas listed in Table 3.

To find a meaningful scope for evaluation, consideration was given to provider, cost, titles (the number of titles from a provider), and usage or full-text downloads. Having collected all of the data on titles, usage, and cost, and linking those disparate data sources together, gave us the ability to collate those data (see Table 7) and break down the most prolific six providers (in terms of titles and cost); the remaining providers are grouped together as Other. Table 7 shows the line item numbers (the number of purchases made in 2012) and the estimated total titles from provider. The distinction in these columns (line items and total titles) is that one line item may account for several titles, and in some cases a line item may account for over 10,000 titles. This ambiguity creates a layer of complexity in analyzing these items. As mentioned with aggregations providing access to large numbers of titles, it is difficult to get the total items from a company like EBSCO or ProQuest because those titles fluctuate. Additionally, the invoice from ProQuest does not contain a listing of all of the journals purchased; because 


\begin{tabular}{|c|c|c|c|c|c|c|c|c|c|}
\hline$=\mathrm{Po}$ & $=$ Name & $\neq$ Title & $=$ Title20 & $=$ Has Jr1 & $\neq$ Found By Issn & $=$ Issn & $\neq$ Price & $=$ Cost Per Download & = Total Download \\
\hline $\begin{array}{l}\text { PO- } \\
999\end{array}$ & $\begin{array}{l}\text { european } \\
\text { journal of } \\
\text { political } \\
\text { economy }\end{array}$ & $\begin{array}{l}\text { European } \\
\text { Journal Of } \\
\text { Political } \\
\text { Economy }\end{array}$ & $\begin{array}{l}\text { Eur J Polit } \\
\text { Econ }\end{array}$ & true & true & $\begin{array}{l}0176- \\
2680\end{array}$ & 959.11 & 3.18 & 302 \\
\hline $\begin{array}{l}\text { PO- } \\
998\end{array}$ & $\begin{array}{l}\text { european } \\
\text { journal of } \\
\text { pharmacology }\end{array}$ & $\begin{array}{l}\text { European } \\
\text { Journal Of } \\
\text { Pharmacology }\end{array}$ & $\begin{array}{l}\text { Eur J } \\
\text { Pharmacol }\end{array}$ & true & true & $\begin{array}{l}0014- \\
2999\end{array}$ & 12792.54 & 10.33 & 1238 \\
\hline
\end{tabular}

FIG. 2. Screen shot of filtered results displayed on the web page, for the ScienceDirect platform from Elsevier.

TABLE 7. Grouping of items purchased in 2012 and number of titles.

\begin{tabular}{lccc}
\hline Provider (invoice from) & Line item numbers & Estimated total titles from provider & Total payment \\
\hline Elsevier & 1,081 & 1,219 & $\$ 3,158,313.30$ \\
EBSCO & 1,225 & 22,378 & $\$ 1,978,703.80$ \\
Harrassowitz & 604 & 604 & $\$ 976,894.79$ \\
ProQuest & 38 & 12,535 & $\$ 675,920$ \\
Springer-Verlang & 2 & 1,330 & $\$ 195,342$ \\
Wiley-Blackwell & 8 & 775 & $\$ 48,489.34$ \\
Other & 516 & 69,123 & $\$ 3,160,043.81$ \\
Totals & 3,474 & 107,964 & $\$ 10,193,706.96$ \\
\hline
\end{tabular}

TABLE 8. Example of cost data on journals showing a journal with a single line item in PO-1 and a package deal with multiple journals splitting the cost in PO-2.

\begin{tabular}{|c|c|c|c|c|c|c|}
\hline Order ID & Journal & ISSN & Database & Provider & Cost & Notes \\
\hline PO-1 & Social Science and Medicine & $0277-9536$ & ScienceDirect Journals & Elsevier & $\$ 5,916.25$ & \\
\hline PO-2 & $\begin{array}{l}\text { Studies in History and Philosophy of } \\
\text { Science. Part A }\end{array}$ & & ScienceDirect Journals & Elsevier & $\$ 1,392.28$ & HPS Combination \\
\hline PO-2 & $\begin{array}{l}\text { Studies in History and Philosophy of } \\
\text { Science. Part B }\end{array}$ & & ScienceDirect Journals & Elsevier & & HPS Combination \\
\hline PO-2 & $\begin{array}{l}\text { Studies in History and Philosophy of } \\
\text { Science. Part C }\end{array}$ & & ScienceDirect Journals & Elsevier & & HPS Combination \\
\hline $\mathrm{PO}-3$ & MD Consult & & MD Consult Core Collection & Elsevier & $\$ 98,000$ & 139 titles \\
\hline
\end{tabular}

of the number of titles that may change and the inability to determine the titles an institution has access to at a given time, it can be extremely complex to evaluate providers such as EBSCO and ProQuest.

As a first study, this analysis aimed for a low number of line items with multiple titles while still maintaining impact from cost, usage, and titles. To achieve this required a further understanding of the relationship between the number of titles and the line items. The items that have one title on a single line provide an easier method to obtain data specific to that title because the cost of that title is typically listed right on that line, as opposed to a database that costs $\$ 5,000$ with 1,000 titles and requires not only an estimation on cost for each title but also requires additional work to look up the titles that might not be precise. Finally, the total payment represents the annual payment made to the provider for the subscription content in 2012.
Elsevier accounts for over $30 \%(30.9 \%)$ of the annual spending on subscriptions, and, within that, Elsevier's ScienceDirect package $(\$ 2,835,149)$ accounts for nearly $90 \%$ of the Elsevier subscription fees in 2012 and over 1,000 line items. Based on this preliminary analysis, the decision was made to focus on a subset of data within Elsevier, the journals that are a part of the ScienceDirect package for this study. The journals purchased via Elsevier are indexed in the ScienceDirect database, and nearly each title has a corresponding cost. There are three examples of Elsevier purchase types (see Table 8): (a) PO-1 is a line item with a single cost, (b) PO-2 displays a package deal with many titles included for one price, and (c) PO-3 shows a database of over 100 titles that has a single price. The most common line item in the ScienceDirect package from Elsevier is similar to PO-1, providing the simplest method of analysis because the title is directly linked to a cost. 
TABLE 9. Listing of funding areas and their representative titles, usage, and cost in 2012

\begin{tabular}{lrrl}
\hline Funding area & Titles & Usage & Cost \\
\hline All & 1,074 & 995,126 & $\$ 2,832,995$ \\
Arts and humanities & 5 & 1,904 & $\$ 4,400$ \\
Business & 59 & 41,048 & $\$ 87,772$ \\
EMS & 122 & 133,733 & $\$ 363,560$ \\
Education & 41 & 52,946 & $\$ 45,542$ \\
Engineering & 133 & 91,487 & $\$ 393,861$ \\
Life sciences & 212 & 225,885 & $\$ 554,908$ \\
P\&MS & 143 & 148,902 & $\$ 763,511$ \\
Social sciences & 33 & 24,728 & $\$ 30,778$ \\
No funding area listed & 326 & 274,493 & $\$ 588,663$ \\
\hline
\end{tabular}

Packages such as the HPS Combination (see Table 8) show how some line items are part of a package deal in which the university spends $\$ \mathrm{~N}$ for $\mathrm{X}$ journals. In this case, the method used to determine the cost of each title is to divide the cost proportionally among the listed titles. For example, in the HPS Combination package, the total cost of $\$ 1,392.28$ is divided by 3 (the number of journals in the package), and each journal is assigned a new price of $\$ 464.09$ per journal. Elsevier has 19 packages similar to the HPS Combination package. These packages account for 47 titles, which is a small subset $(4.4 \%)$ of the ScienceDirect titles from Elsevier. Likewise, the financial impact is similar; these package deals account for $\$ 170,326.37$ (5.39\%).

The Elsevier journals also more precisely match the cost data with the usage data than (perhaps) an aggregator with thousands of changing titles. In this analysis, most of the time, the ability to match ISSN instead of matching with the journal title adds a higher level of precision when linking the JR1 reports to the financial data because 887 of the 1,074 (82.6\%) Elsevier items purchased in 2012 can be matched via ISSN. If no match was made via either ISSN or title, the journal was considered to have no usage. This is in part because of the matching ISSN and because many of the Elsevier line items are for a single journal and not for database packages, which in some cases may consist of thousands of titles.

The overview of funding areas for all the journals within the ScienceDirect database illustrates a disparity in particular funding areas; however all are represented with respective title, usage, and cost in order to evaluate consistently. Arts and humanities can be considered an outlier in this data selection because of the significance of the disparity in journal numbers represented (see Table 9).

\section{Data Categorization and Ranking}

Once we had selected the Elsevier's ScienceDirect package, we had to categorize the journals based on the funding area (see Table 3). The "all" funding area is distinct because it represents all the journals from the ScienceDirect database without regard to category. This was done to see what funding areas (if any) shared means with a more holistic approach that disregards funding area. For example, if our analysis shows that all of our funding areas do not have a significant difference from the "all" category, this could imply that the funding area distinction is not truly providing us with any valuable classification. Conversely, if the funding area "all" is significantly different from other funding areas, this is further evidence that any examination of journal price and/or usage should account for this categorization of funding area. No funding area listed indicates journals that are purchased within funding areas indistinguishable to a particular discipline category (e.g., arts and humanities, business, education).

In the first two hypotheses ( $\mathrm{H} 1$ and $\mathrm{H} 2)$ the titles are ranked by usage, and in the next two hypotheses ( $\mathrm{H} 3$ and $\mathrm{H} 4)$ the titles are ranked by cost. In $\mathrm{H} 1$ and $\mathrm{H} 3$, the independent variable is usage, and in $\mathrm{H} 2$ and $\mathrm{H} 4$ the independent variable is cost; in all four hypotheses the one dependent variable is titles (i.e., titles within a funding area). This creates a comprehensive view of the discrepancy of both usage and cost among titles when ranking by either usage or cost. In each case, the data are ranked appropriately (most expensive or most used to least expensive or least used) and then divided into one-thirds: the most expensive (highest $33.3 \%$ by cost), middle most expensive (next highest $33.3 \%$ by cost), and least expensive (lowest $33.3 \%$ by cost), and likewise for usage/full-text download data (highest 33.3\%, next highest 33\%, and lowest $33 \%$ by usage). The data used for comparison among the categories were the least expensive and the least used because it was demonstrated that normalizing the data to the lower one-third eliminates any of the variance that might be caused by the more heavily used or more expensive journals. Additionally, ranking by both cost and usage and comparing the variance of cost and usage can further illustrate any parity that may be created by ranking and comparing the same factor. For example, some may assume that the variance of mean cost is very little among categories for the less expensive journals and that the variance of usage may be small among the categories for the infrequently journals. The design of this analysis prevents this bias by testing both areas in both rankings.

For some journals we were not able to obtain usage statistics based on the methods used to link journal usage data and our financial data. If a journal in a funding area did not have usage data, it was eliminated from the bottom one-third, and we selected a substitute journal using the next journal on the list in ranked order.

\section{Results}

Once we had our data selected and categorized, we imported the data into Minitab, which we used to run the one-way ANOVA to compare the differences among the variance means of funding area categories in usage and cost, ranking separately by both usage and cost. For all ANOVAs 
represented, the critical value of $p$ was 0.05 . We also used Tukey's test as the post hoc analysis to uncover where the differences in the categories existed.

$\mathrm{H} 1$ (Usage is unevenly distributed among the 10 funding areas based on the least used one third (33\%) of all journals.) and $\mathrm{H} 2$ (Cost is unevenly distributed among the 10 funding areas based on the least used one third (33\%) of all journals.) used data from ranking the journals by usage first (see Table 10). With regard to H1, the ANOVA indicated that there is a significant $(p<0.001)$ difference among funding areas in usage. The post hoc analysis (Table 11) shows a significant difference among multiple funding area groups. In fact, the post hoc analysis shows us that education is significantly different from all other funding areas in terms of usage among the bottom one third of journals within that funding area. Additionally, life sciences do not have a significantly different mean from three other funding areas (earth and mineral science, social sciences, and arts and humanities). Arts and humanities (as shown in Table 10) is somewhat of an outlier to begin with because there are only two journals included in this analysis. Based on this relatively small sample size from the arts and humanities, it is fair to say that life sciences is significantly different from all but two funding areas.

TABLE 10. Bottom one third of journals based on usage by funding area in 2012.

\begin{tabular}{lrrl}
\hline Funding area & Titles & Usage & Cost \\
\hline All & 340 & 75,243 & $\$ 573,262$ \\
Arts and humanities & 2 & 284 & $\$ 2,068$ \\
Business & 19 & 3,868 & $\$ 16,344$ \\
EMS & 38 & 9,523 & $\$ 71,080$ \\
Education & 15 & 11,560 & $\$ 6,623$ \\
Engineering & 42 & 8,880 & $\$ 88,951$ \\
Life sciences & 69 & 20,174 & $\$ 121,562$ \\
P\&MS & 44 & 6,805 & $\$ 134,609$ \\
Social sciences & 11 & 2,464 & $\$ 8,457$ \\
No funding area listed & 104 & 22,534 & $\$ 102,719$ \\
\hline
\end{tabular}

TABLE 11. Post hoc analysis for usage by funding area.

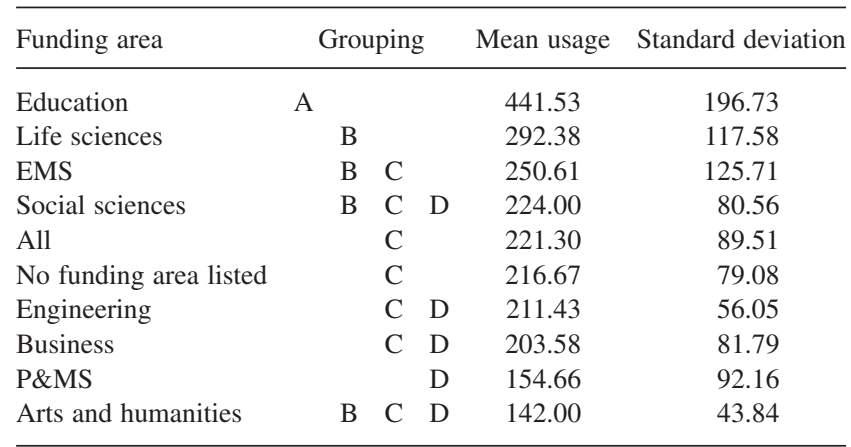

Note. Means that do not share a grouping letter are significantly different $(p<0.001)$.
However, this distinction is not necessarily a negative; the mean usage for even the lowest one-third used journals is significantly more than the mean usage for the least used journals in other funding areas. Education in particular and to a lesser extent life sciences, earth and mineral sciences, and social sciences all have a significantly higher mean usage for even their least used journals compared with the least used journals from the other funding areas. Physical and mathematical sciences (P\&MS) has the lowest mean usage, except for arts and humanities, within its least used journals, with an average of 154.66 full-text downloads per journal in a year. This proves that, even when ranking journals by usage and taking the least used one third of journals within each funding area, there is still a significant statistical difference in the usage of these journals among the funding areas, so $\mathrm{H} 1$ is fully supported.

For $\mathrm{H} 2$, the ANOVA results demonstrate that there is a significant difference $(p<0.001)$ among the costs of the 10 funding areas ranked by usage from each funding area. The post hoc analysis (Table 12) displays the groups for which a significant difference exists; P\&MS is not significantly different from engineering, earth and mineral sciences, and arts and humanities; however, arts and humanities has such a small sample (two journals) that, practically speaking, it would make sense to say that P\&MS is significantly different from all but two funding areas. Additionally, P\&MS has the highest mean cost for journals that are in the lowest one third of journals in this funding area by usage. P\&MS was near the lowest means (Table 11) for usage and highest means for cost (Table 12) in this evaluation. There were fewer groupings in cost than in usage; however, there is a significant difference in means, which confirms H2. There is a distinction in both usage and cost among the funding areas when ranking the journal titles by usage and evaluating the least used one third (33\%) of journal titles; however, when ranking the titles by usage, the larger difference within the funding areas is in journal title usage than in journal title cost.

The following analysis for H3 and H4 changes the mechanism for ranking journals. The journals are still classified by funding area but are then ranked by price

TABLE 12. Post hoc analysis for cost by funding area.

\begin{tabular}{|c|c|c|c|c|c|}
\hline Funding Area & \multicolumn{3}{|c|}{ Grouping } & Mean cost & Standard deviation \\
\hline P\&MS & \multicolumn{3}{|l|}{ A } & $\$ 3,059$ & 3,699 \\
\hline Engineering & A & \multicolumn{2}{|l|}{ B } & $\$ 2,118$ & 1,175 \\
\hline EMS & A & B & $\mathrm{C}$ & $\$ 1,871$ & 1,204 \\
\hline Life sciences & & B & $\mathrm{C}$ & $\$ 1,762$ & 1,207 \\
\hline All & & B & & $\$ 1,686$ & 1,831 \\
\hline Arts and humanities & $\mathrm{A}$ & B & $\mathrm{C}$ & $\$ 1,034$ & 552 \\
\hline Nothing & & & $\mathrm{C}$ & $\$ 988$ & 913 \\
\hline Business & & B & $\mathrm{C}$ & $\$ 860$ & 515 \\
\hline Education & & B & $\mathrm{C}$ & $\$ 771$ & 382 \\
\hline Social sciences & & B & $\mathrm{C}$ & $\$ 769$ & 322 \\
\hline
\end{tabular}

Note. Means that do not share a grouping letter are significantly different $(p<0.001)$. 
TABLE 13. Bottom one third of journals based on annual subscription price for the journal in 2012 by funding area.

\begin{tabular}{lrrl}
\hline Funding area & Titles & Usage & Cost \\
\hline All & 340 & 248,128 & $\$ 224,807$ \\
Arts and humanities & 2 & 428 & $\$ 1,044$ \\
Business & 19 & 6,352 & $\$ 12,359$ \\
EMS & 38 & 15,857 & $\$ 42,913$ \\
Education & 15 & 6,623 & $\$ 11,560$ \\
Engineering & 42 & 15,667 & $\$ 54,539$ \\
Life sciences & 69 & 58,143 & $\$ 60,494$ \\
P\&MS & 44 & 19,045 & $\$ 70,301$ \\
Social sciences & 11 & 7,195 & $\$ 5,585$ \\
No funding area listed & 104 & 72,487 & $\$ 36,590$ \\
\hline
\end{tabular}

TABLE 14. Post hoc analysis for usage by funding area.

\begin{tabular}{|c|c|c|c|c|c|c|}
\hline \multirow{2}{*}{$\frac{\text { Funding area }}{\text { Life sciences }}$} & \multicolumn{4}{|c|}{ Grouping } & \multirow{2}{*}{$\frac{\text { Mean usage }}{871.6}$} & \multirow{2}{*}{$\frac{\text { Standard deviation }}{1,141.5}$} \\
\hline & A & & & & & \\
\hline All & A & B & & & 728.8 & 941.8 \\
\hline Nothing & A & B & $\mathrm{C}$ & & 725.4 & 869.7 \\
\hline Social sciences & A & B & $\mathrm{C}$ & $\mathrm{D}$ & 654.1 & 551.5 \\
\hline EMS & & B & $\mathrm{C}$ & $\mathrm{D}$ & 463.8 & 333.6 \\
\hline Education & A & B & $\mathrm{C}$ & $\mathrm{D}$ & 441.5 & 196.7 \\
\hline P\&MS & & & $\mathrm{C}$ & $\mathrm{D}$ & 434.2 & 676.6 \\
\hline Engineering & & & & $\mathrm{D}$ & 400.9 & 428.5 \\
\hline Business & & B & $\mathrm{C}$ & $\mathrm{D}$ & 334.3 & 325.0 \\
\hline Arts and humanities & A & B & $\mathrm{C}$ & $\mathrm{D}$ & 214.0 & 145.7 \\
\hline
\end{tabular}

Note. Means that do not share a grouping letter are significantly different $(p<0.001)$

(Table 13), focusing on the least expensive one third (33\%) of the journals by funding area and analyzing the differences (if any) based on the funding area classification.

With regard to $\mathrm{H} 3$ (Usage is unevenly distributed among the 10 funding areas based on the least expensive one third [33\%] of all journals.), the ANOVA results indicate a significant difference $(p=0.021)$ among the mean usage for the 10 funding areas. The post hoc analysis (see Table 14) used was the Fisher's individual error rate to find the differences among the categories. This analysis exhibits four different groupings among the funding areas and confirms that the distribution of usage within these funding areas is different, fully supporting $\mathrm{H} 3$.

For H4 (Cost is unevenly distributed among the 10 funding areas within the least expensive one third [33\%] of all journals.), the ANOVA results indicate there is a significant difference $(p<0.001)$ among the cost means of the least expensive $33 \%$ of journals from the 10 different funding areas. Even it is interesting to note that, even ranking the journals by cost, there is still a significant difference in cost among the funding areas. The post hoc analysis (see Table 15) shows a significant difference between $\mathrm{P} \& \mathrm{MS}$ and all other funding areas in cost. This indicates that even the least expensive journals in P\&MS are significantly different from those of other funding areas. Engineering and
TABLE 15. Post hoc analysis for cost by funding area.

\begin{tabular}{|c|c|c|c|c|c|c|}
\hline \multirow{2}{*}{$\frac{\text { Funding area }}{\text { P\&MS }}$} & \multicolumn{4}{|c|}{ Grouping } & \multirow{2}{*}{$\frac{\text { Mean cost }}{\$ 1,615}$} & \multirow{2}{*}{$\frac{\text { Standard deviation }}{757.8}$} \\
\hline & $\mathrm{A}$ & & & & & \\
\hline Engineering & & B & & & $\$ 1,308$ & 308.1 \\
\hline EMS & & B & & & $\$ 1,171$ & 525.2 \\
\hline Life sciences & & $\mathrm{C}$ & & & $\$ 920$ & 344.0 \\
\hline Education & & $\mathrm{C}$ & $\mathrm{D}$ & & $\$ 770$ & 381.9 \\
\hline All & & & $\mathrm{D}$ & & $\$ 661$ & 305.0 \\
\hline Business & & $\mathrm{C}$ & D & & $\$ 650$ & 110.0 \\
\hline Arts and humanities & & $\mathrm{B} \quad \mathrm{C}$ & D & $\mathrm{E}$ & $\$ 522$ & 171.7 \\
\hline Social sciences & & & D & $\mathrm{E}$ & 507.8 & 110.3 \\
\hline No funding area listed & & & & $\mathrm{E}$ & 368.0 & 213.9 \\
\hline
\end{tabular}

Note. Means that do not share a grouping letter are significantly different $(p<0.001)$.

earth and mineral sciences share a grouping with arts and humanities, again, although arts and humanities can be considered an outlier because of the small percentage of the sample in journal titles and annual subscription cost. The no funding area listed category has the lowest mean cost among journals within this classification, which may indicate that other funding areas could benefit from appearing less expensive if these journals were appropriately categorized. The difference among these funding areas supports $\mathrm{H} 4$, which is that the cost is unevenly distributed among the funding areas within the least expensive one third of journals from those funding areas. There is a distinction in both usage and cost among the funding areas when ranking the journals by cost and evaluating the least expensive one-third (33\%); however, when ranking the titles by cost, the larger difference within the funding areas is in journal cost than in the journal usage.

\section{Discussion}

The data confirming the four hypotheses address the broader research question (Is there a significant difference in the cost and usage among titles for the various funding areas?). Yes, there is a significant difference in cost and usage for these titles across the various funding areas, and when examining the value of these journals this classification (a title's funding area) should be considered in terms of meeting the institutional goals with regard to electronic resources.

Given that there is a significant statistical difference among the categories, it makes sense to compare the accumulation of all nine individual categories (arts and humanities, business, earth and materials sciences, education, engineering, life sciences, P\&MS, social sciences, and no funding area listed) with the "all" category to determine whether there is a difference, practically speaking, in the cost and usage of the least expensive and least used journals. The difference in content (journal titles) is relatively negligible; there are 344 titles in the individual categories and 340 titles in the "all" category. 


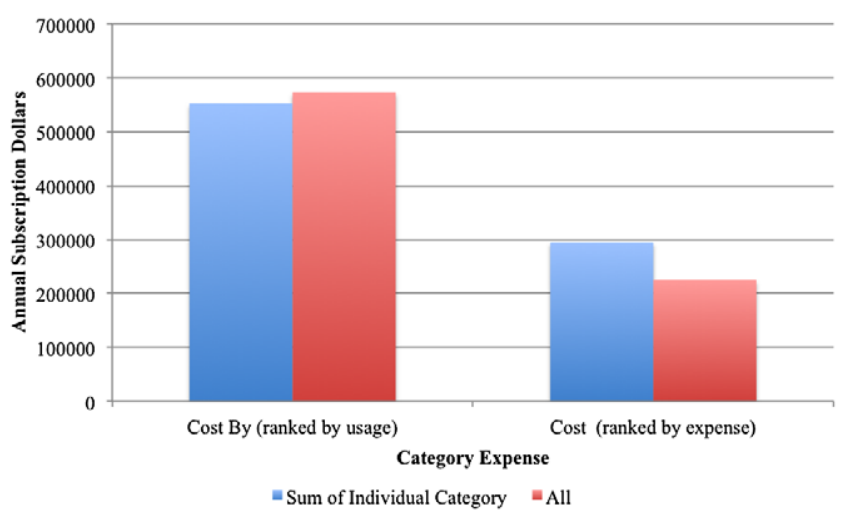

FIG. 3. Comparison of the cumulative expense of the individual funding areas with the "all" category, which ignores funding area. [Color figure can be viewed in the online issue, which is available at wileyonlinelibrary.com.]

For example, we can compare these categorizations to see what makes the most significant impact if the institutional strategy goal was to save money and reduce expenses on electronic resources. Would the accumulation of all of the expenses saved by the nine individual categories be comparable to the money saved when ignoring the funding areas and just eliminated journals based on being the least expensive or the least used? There is a large distinction based on how we rank the journals (See Figure 3), but there is a much smaller difference between the dollars saved when looking at adding up all of the individual funding areas and comparing those individual funding areas with the method that ignores the funding areas ("all").

When ranking the journals by least used, the savings would be nearly doubled of that realized when ranking the journals by least expensive. This would indicate that to save the most money for the institution (if that were the goal) the best way to do this would be to rank journals by usage and to eliminate the least used within each category. The "all" category would provide an inequitable impact on users of various funding areas that it has ignored and would not yield much in the way of increased savings over an evaluation on individual funding areas.

As is the case with expense, there is a statistically significant difference among the categories' usage when ranking by usage and cost. Examining the significance of the usage difference between the summation of all nine individual funding areas (arts and humanities, business, EMS, education, engineering, life sciences, P\&MS, social sciences, and no funding area listed) compared with the "all" funding area (see Figure 4), we can further understand the practical impact between these methods of comparison. There is little practical difference in usage between summation of the individual categories and the "all" category that ignores funding areas completely. Again, the difference in content is negligible; there are 344 titles in the individual funding areas and 340 titles in the "all" category.

For example, if the institution were trying to determine which method would impact users the least, then ranking by

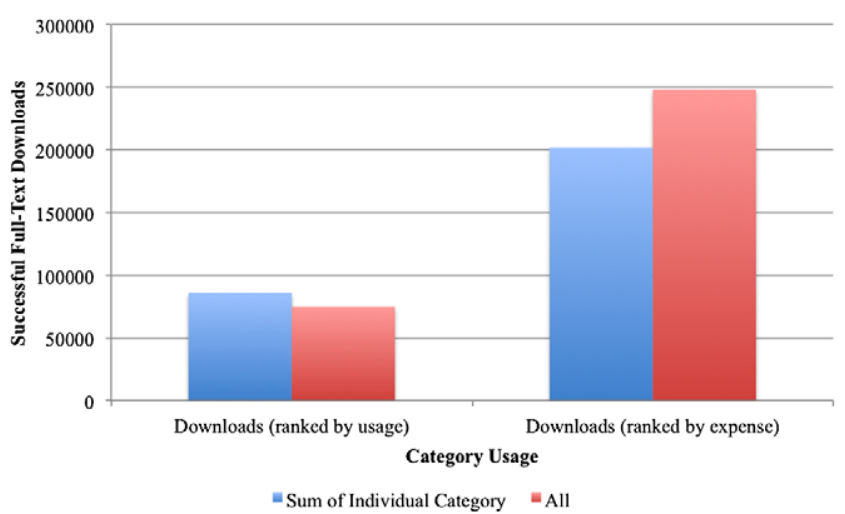

FIG. 4. Comparison of the cumulative usage of individual funding areas with the "all" category, which ignores funding area. [Color figure can be viewed in the online issue, which is available at wileyonlinelibrary.com.]

usage and ignoring "all" may seem to be the logical decision; however; this decision may be completely inequitable among particular users that have a large number of journals from a particular discipline that is funded by that area. Additionally, if we consider the significance of the difference in usage between these two methods $(86,000$ downloads in individual categories, and 75,000 in the "all" category), it is less significant. Over the course of the year, there are 11,000 fewer downloads among 340 journals; this equates to about 32 downloads per journal title that we save by choosing the "all" method instead of looking at individual categories. Given that there is a significant statistical difference in usage for the categories, it seems to be worth looking at usage by funding area; although the total impact on users would be greater $(86,000$ downloads compared to 75,000 downloads), by analyzing the funding areas individually the impact would likely be impartial.

Based on the results of this analysis and affirming that these journals should be analyzed by the individual funding area, it is possible to create a breakdown of titles, usage, and cost (see Figure 5) by funding area. Keep in mind that any journals without usage data were omitted from this chart because we cannot accurately analyze that key component of value for those resources. This visualization helps illustrate why inequity may exist if we do not consider funding area and happen to be comparing journals from P\&MS with journals from arts and humanities or even education or social sciences. Furthermore, we can see that we have more journal titles and usage associated with no funding area than we have associated with any single funding area; this would indicate that there is precision to be gained in our evaluation if we had an internal funding area to associate with those journal titles and their cost and use.

This analysis indicates that there is a significant difference in usage and cost among titles in various funding areas. The difference in these metrics (usage and cost) across funding areas indicates that titles should be evaluated based on funding area categorization. For example, it would not be equitable to compare the use of titles in arts and humanities 


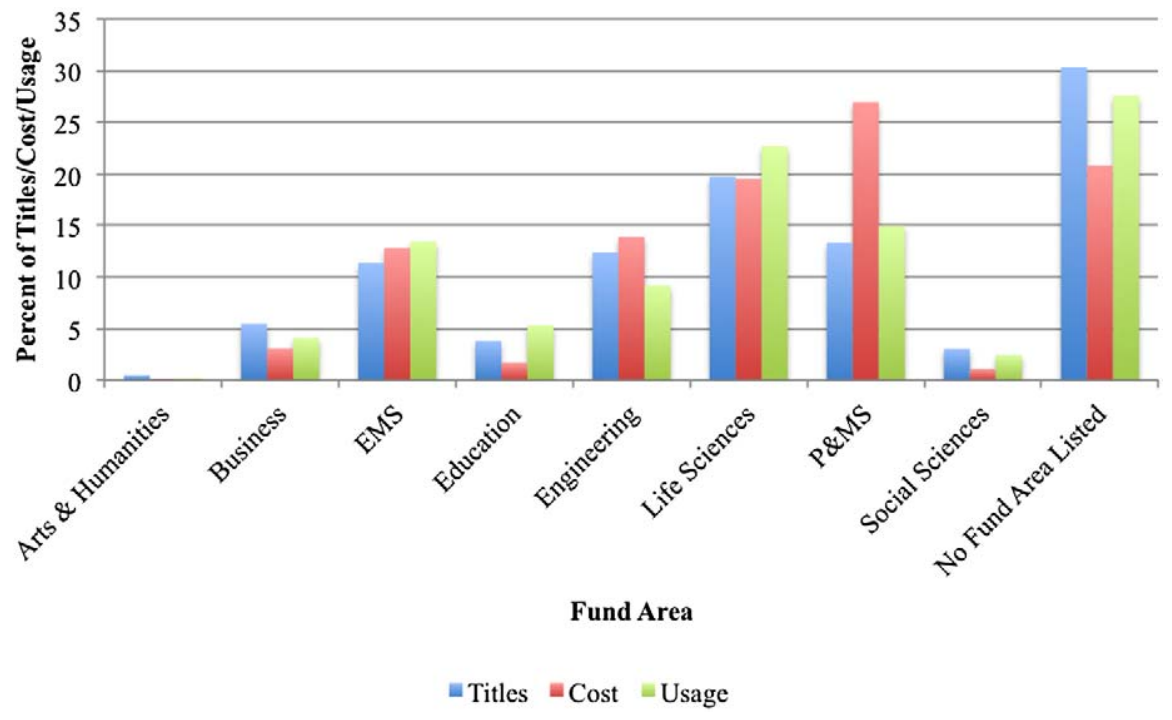

FIG. 5. Percentage for each funding area for cost, titles, and usage within the ScienceDirect package for 2012. [Color figure can be viewed in the online issue, which is available at wileyonlinelibrary.com.]

with the use of titles funded by P\&MS; evaluating journals without the funding area classification would be comparing apples with oranges. To compare apples with apples, we should compare the usage of journal titles within the funding area for which they were purchased, the P\&MS journal titles in one analysis and the arts and humanities journal titles in another analysis.

The focus of titles analyzed in this model is journals with low usage and cost relative to other journals in a particular funding area. The primary reason to concentrate on the least used and less expensive journals is that the least used journals provide potential cost savings if they are used so infrequently that removing them from the collection would not affect library users. If a library were faced with a need to weed certain journals from a collection, the least-used journals would provide the first area for investigation. The ultimate goal is to inform collection management positively and not to impact users negatively. The least used 340 titles cumulatively represent less than $8 \%$ of use and over $20 \%$ $(\$ 573,262)$ of the annual cost of journals in the ScienceDirect database. This portrays a scenario with resources representing low usage and significant cost; the journals represented in this situation are candidates for further evaluation (and potential elimination) to determine the value they have.

In each of these analyses, we eliminated any journals that had no usage data to report. Nearly $95 \%$ of the journals in the ScienceDirect package had these data to create metrics for evaluation; however, it is worthwhile analyzing what categories have the highest representation of titles and cost that have no usage data available. These journals provide no ability for any measurement or evaluation within the community that the institution serves, and they should undergo further investigation to understand whether there is a alternative reason why these journals do not provide usage data. The 56 journals that lack these data cost in total $\$ 196,786$, and we can see (Figure 6) the funding areas that represent the largest portions of that cost. Additionally, we can examine which funding areas represent an uneven distribution of titles or contents that do not report funding data; by and large, this chart (Figure 6) indicates that the percentages of titles and cost within each funding area are relatively similar. The outlier may be engineering, which seems to represent nearly twice the cost of titles without usage data.

\section{Implications}

\section{Theoretical Implications}

The aim of this research is to provide the foundation for a framework to evaluate electronic journal resources. There are several layers of complexity behind electronic resources that create a difficult environment in which to perform a thorough evaluation. This research extends the use of cost, titles, and usage as metrics to be used not only to determine where there is real value but also where there is content that does not seem to be providing value. A novel approach to comparing the impact of a holistic ("all" funding area) and the individual funding areas (arts and humanities, business, earth and mineral sciences (EMS), education, engineering, life sciences, P\&MS, social sciences, no funding area listed) is discussed. The model can be extended further to a larger sample of journals and to databases and aggregations.

A study such as this can begin a discussion of which journals are no longer necessary to include in library collections and what impact various methods of analysis will have on funding, usage, and content as well as how they pertain to 


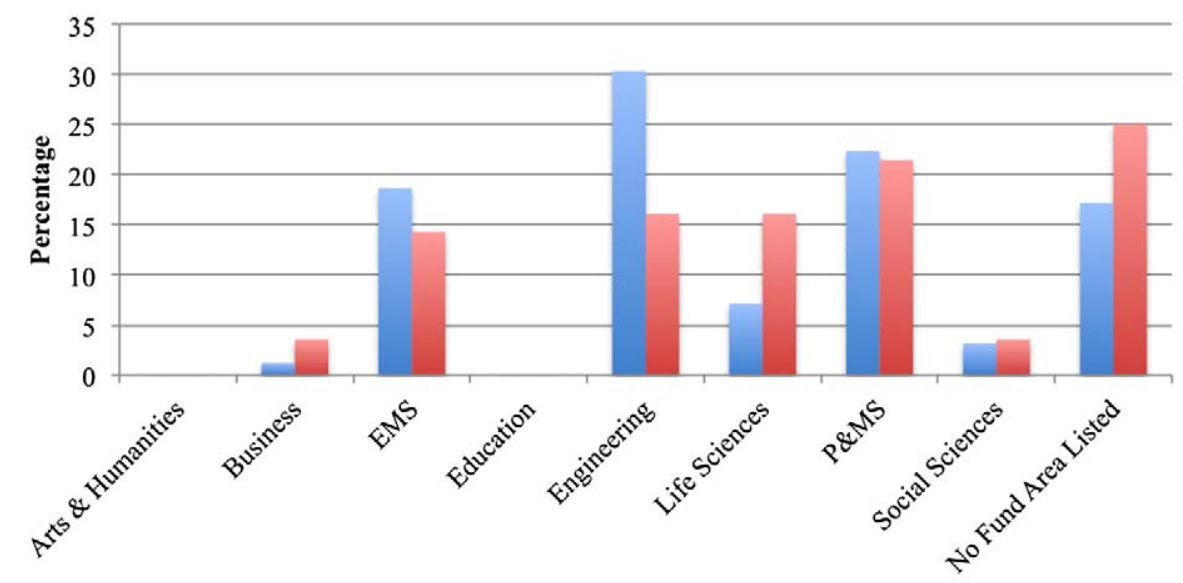

Fund Areas

Cost $=$ Titles

FIG. 6. Funding areas and their representation within the total cost, along with content (titles) of journal with no usage data. [Color figure can be viewed in the online issue, which is available at wileyonlinelibrary.com.]

the mission of the institution (negatively impacting users vs. saving money). A further analysis can include metrics on impact factor and local citations for titles within aggregations as well as journals, along with other cost, titles, and usage metrics. There has been significant work on the various metrics used to evaluate journals, such as impact factor, Eigenfactor, h-index variants, and a more recent metric, the author affiliation index (this measure relies on the idea that authors from prominent universities do better research; Rokach, 2012); this work can help to create the foundation for a model to pursue a more comprehensive method of evaluation. This work quantitatively shows that any evaluation of journals should consider the funding area or the research area that the journal serves to distribute the analysis more equitably across the fields that a university serves.

\section{Practical Implications}

One of the primary considerations given to journal selection should be how easily we can evaluate the use of the journal. To manage resources (i.e., titles) effectively, there needs to be knowledge about cost and usage, as with any practical application of web analysis (Phippen, Sheppard, \& Furnell, 2004). The size (both the amount of data and the number of titles) and complexity require that this be done in a streamlined fashion. The only way to streamline this information is if it is aggregated in a single way; for example, journals that do not provide usage data through JR1 reports should not be considered for purchase unless there are truly extenuating circumstances or unless this knowledge could be used to pressure the publishers to provide usage data. The goal should be to determine how to get all journals to report usage statistics and not to find a reason for an exception.
On the internal administration side, consideration should be given to understanding the items that are purchased without any indication of the purchasing funding area. An understanding of the funding area and the usage data is something that can obviously benefit libraries as well as providers because they can gain a solid understanding of which journals really do provide value to the customers and that may merit more resources to publishing, curating, etc. Furthermore, the tool developed to perform this evaluation can be enhanced to analyze additional metrics for other subscription types such as aggregations and databases to allow for a more timely and efficient evaluation of journals that is accessible to librarians and faculty members so that they can all see the data driving these decisions.

\section{Conclusions}

The ideal state to reach for research libraries is one in which an analytical framework exists for each library to evaluate electronic resources in order to determine value and efficient use. Libraries should manage their own journal usage and understand their own researchers; they cannot rely on results from global metrics (such as impact factor) or studies from other universities to determine the selection of effective journals. Such a framework also allows libraries to analyze not only the journals but also the accuracy of various methods and to determine what methods illustrate similar value within journals. The methods presented here may lead to a greater credibility for those methods or at least greater consistency in evaluating journals.

This article quantitatively illustrates the need to categorize journal evaluation. Electronic resources provide tremendous value to the community that they serve; research at many large institutions relies on the access provided to these 
journals. This analysis quantitatively shows that, when analyzing journals, accuracy and equity can be increased by categorizing journals based on the area of research that they serve. The high value that these resources provide is precisely why they should be evaluated and analyzed to accentuate those of particular importance and to re-evaluate the necessity of those that either are not used or provide no mechanism for further evaluation. To perform this analysis, we have begun to develop an application to automate some of the processes in integrating the disparate data sources that aggregate information on cost and usage. Future research includes applying our method to the entire data set of an institution across all publishers, which will require some cross-publisher leveling and metric alignment, on which we are working. We are also going to examine search log analysis (Jansen, 2008) for insight into article demand and future content. Also, enhancements to this application to make these processes repeatable based on annual data and collating additional data points, such as citations, impact factor, cost per use, articles, article influence score, are being explored. An application like this can aid in measuring journals that should be considered outliers based on certain criteria and warrant further investigation to make digital collection administration of electronic resources a more manageable task.

\section{Acknowledgments}

We would like to thank Jaime Jameson, Amber Hatch, James DeVoss, and Bob Alan for their support and patience.

\section{References}

Bartsch, R.A., \& Tydlacka, B.L. (2003). Student perceptions (and the reality) of percentage of journal articles found through full-text databases. Research Strategies, 19(2), 128-134.

Bensman, S.J., Smolinsky, L.J., \& Pudovkin, A.I. (2010). Mean citation rate per article in mathematics journals: Differences from the scientific model. Journal of the American Society for Information Science and Technology, 61(7), 1440-1463.

Blecic, D.D., Wiberley Jr., S.E., Fiscella, J.B., Bahnmaier-Blaszczak, S., \& Lowery, R. (2013). Deal or no deal? Evaluating big deals and their journals. College \& Research Libraries, 74(2), 178-194.

Blessinger, K., \& Olle, M. (2004). Content analysis of the leading general academic databases. Library Collections Acquisitions \& Technical Services, 28(3), 335-346.

Chambers, M.B., \& So, S. (2004). Full-text aggregator database vendors and journal publishers: A study of a complex relationship. Serials Review, 30(3), 183-193.

Coleman, A. (2007). Assessing the value of a journal beyond the impact factor. Journal of the American Society for Information Science and Technology, 58(8), 1148-1161.

De Bellis, N. (2014). History and Evolution of (Biblio)Metrics. Beyond Bibliometrics: Harnessing Multidimensional Indicators of Scholarly Impact, 23.

Derven, C., Kendlin, V., (2011). Evidence-based librarianship: A case study of a print resource cancellation project. The Journal of Academic Librarianship, 37(2), 166-170.
Duranceau, E.F. (2002). E-journal package-content tracking services. Serials Review, 28(1), 49-52.

Duy, J., \& Vaughan, L. (2003). Usage data for electronic resources: A comparison between locally collected and vendor-provided statistics. Journal of Academic Librarianship, 29(1), 16-22.

Duy, J., \& Vaughan, L. (2006). Can electronic journal usage data replace citation data as a measure of journal use? An empirical examination. Journal of Academic Librarianship, 32(5), 512-517.

Enssle, H.R., \& Wilde, M.L. (2002). So you have to cancel journals? Statistics that help. Library Collections, Acquisitions \& Technical Services, 26(3), 259-281.

Furlough, M.J. (2012). Opening access to research: From concepts to actions. Open Access Week: The Pennsylvania State University.

Jansen, B.J. (2008). The methodology of search log analysis. In B.J. Jansen, A. Spink, and I. Taksa (Eds), Handbook of Research on Web Log Analysis (pp. 100-123). Hershey, PA: IGI.

Jansen, B.J. (2009). Understanding user-web interactions via web analytics. Synthesis Lectures on Information Concepts, Retrieval, and Services, 1(1), 1-102.

Jansen, B.J., \& Molina, P. (2006). The effectiveness of web search engines for retrieving relevant ecommerce links. Information Processing \& Management, 42(4), 1075-1098.

King, D.W., \& Tenopir, C. (1998). Designing electronic journals with 30 years of lessons from print. Journal of Electronic Publishing, 4(2), 1-29.

Kyrillidou, M., Morris, S., \& Roebuck, G. (2013). ARL Statistics 20112012, Association of Research Libraries, Washington, DC, available at: http://publications.arl.org/ARL-Statistics-2011-2012/45 (accessed 22 March 2015).

Leon, L., \& Kress, N. (2012). Looking at resource sharing costs. Interlending \& Document Supply, 40(2), 81-87.

McDonald, J., \& Van d Velde, E.F. (2004). The lure of linking. Link resolvers are essential to getting optimal usage of electronic content. Library Journal, 129(6), 32-34.

Medeiros, N. (2007). Usage statistics of e-serials. Binghamton, NY: The Haworth Press.

Metz, P. (1992). Thirteen steps to avoiding bad luck in a serials cancellation project. Journal of Academic Librarianship, 18(2), 76-82.

Montgomery, C.H. (2000). Measuring the impact of an electronic journal collection on library costs: A framework and preliminary observations. D-Lib Magazine, 6(1), 37-52.

Needleman, M.H. (2006). The NISO standardized usage statistics harvesting initiative (SUSHI). Serials Review, 32(3), 216-217.

Neeley, J.D. (1981). The management and social science literatures: An interdisciplinary cross-citation analysis. Journal of the American Society for Information Science and Technology, 32(3), 217-223.

Ortiz-Cordova, A., \& Jansen, B.J. (2012). Classifying web search queries in order to identify high revenue generating customers. Journal of the American Society for Information Science and Technology, 63(7), 1426-1441.

Phippen, A., Sheppard, L., \& Furnell, S. (2004). A practical evaluation of web analytics. Internet Research, 14(4), 284-293.

Rokach, L. (2012). Applying the publication power approach to artificial intelligence journals. Journal of the American Society for Information Science and Technology, 63(6), 1270-1277.

Schwartz, C. (2000). Digital libraries: An overview. Journal of Academic Librarianship, 26(6), 385-393.

COUNTER (2012). COUNTER code of practice, Release 4. April 2012. http://www.projectcounter.org/r4/COPR4.pdf (Accessed 23 October 2013).

Vaughan, J. (2012). Investigations into library web-scale discovery services. Information technology and libraries, 31(1), 32-82.

West, W.L., Miller, H.S., \& Wilson, K. (2011). Electronic journals: Cataloging and management practices in academic libraries. Serials Review, 37(4), 267-274. 